PUBLIK: Jurnal Manajemen Sumber Daya Manusia, Administrasi dan Pelayanan Publik Sekolah Tinggi Ilmu Administrasi Bina Taruna Gorontalo Volume VI Nomor 1 Juni 2019

\title{
KEMAMPUAN PETUGAS PENGELOLA DALAM PEMANFAATAN TEMPAT PELELANGAN IKAN (TPI) DI KELURAHAN TENDA KECAMATAN HULONTHALANGI KOTA GORONTALO
}

\author{
Fauziah Rauf \& Ellys Rachman \\ STIA Bina Taruna Gorontalo \\ bukujurnalstia@binataruna.ac.id ${ }^{1} \&$ ellysrachman12@gmail.com ${ }^{2}$
}

\begin{abstract}
ABSTRAK
Penelitian ini bertujuan untuk mengetahui tentang Kemampuan Petugas Pengelola dalam Pemanfaatan Tempat Pelelangan Ikan (TPI) di Kelurahan Tenda Kecamatan Hulonthalangi Kota Gorontalo. Jenis penelitian yaitu deskriptif pendekatan kualitatif. Tehnik pengumpulan data dilakukan melalui wawancara dengan sejumlah infroman, observasi dan dokumentasi. Fokus penelitian terdiri dari Pengetahuan, koordinasi dan tanggung jawab.

Hasil penelitian menyimpulkan bahwa dilihat dari dimensi pengetahuan belum menunjang; dilihat dari aspek koordinasi belum optimal dilakukan; dilihat dari aspek tanggung jawab masih kurang mendukung. Sehingga disarnkan perlunya pimpinan dan staf TPI untuk dapat meningkatkan pengetahuan melalui pendidikan formal dan non formal, agar memiliki wawasan dan kemampuan dalam melaksanakan tugas yang di embannya. Perlunya pimpinan dan staf TPI dalam melakukan pengelolaan dan pemanfaatan TPI untuk melakukan koordinasi dan singronisasi secara intensif kepada instansi terkait dan masyarakat, agar terwujud kerjasama yang harmonis dalam mengembangan TPI ke depan yang lebih cerah dan sesuai harapan. Perlunya pimpinan dan staf TPI memiliki tanggung jawab yang tinggi dalam pelaksanaan tugas, agar rencana yang telah ditetapkan dapat terwujud dengan baik.
\end{abstract}

\section{Kata Kunci: Kemampuan; Pengelola; Tempat Pelelangan Ikan}

\section{PENDAHULUAN}

Komisi nasional pengkaji
sumber daya perikanan laut melaporkan bahwa potensi sumber daya perikanan laut Indonesia adalah 6,4 juta pertahun dengan potensi terbesar dari ikan pelagis kecil yaitu sebesar 3,2 juta ton $(52,24 \%)$, dan ikan pelagis besar 0,97 juta ton $(15,81)$. Saat ini pemanfaatan sumber daya perikanan baru mencapai 45 juta ton / tahun, dan budidaya pesisir sekitar 5 juta ton pertahun. Sementara itu, total produksi perikanan budidaya, termasuk dari perairan darat, baru mencapai 1,6 juta ton $(0,3 \%)$. Saat ini, Indonesia merupakan produsen ikan terbesar kelima di dunia dengan volume produksi 6,3 juta ton pertahun.

Pemerintah daerah bertanggung jawab juga memberdayakan nelayan kecil dan pembudidayaan ikan serta pengembangam SDM dengan adanya 
PUBLIK: Jurnal Manajemen Sumber Daya Manusia, Administrasi dan Pelayanan Publik Sekolah Tinggi Ilmu Administrasi Bina Taruna Gorontalo Volume VI Nomor 1 Juni 2019

pembangunan Tempat Pelelangan ikan (TPI). Tempat Pelelangan Ikan (TPI) sebagai bagian dari pembangunan fasilitas perikanan ini diharapkan akan dapat meningkatkan nelayan dalam melaksanakan aktivitas produktifnya, baik dalam hal pendaratan ikan, pelelangan, pengolahan, maupun proses pemasarannya, serta diharapkan mengurangi kebocoran hasil tangkapan.

Berdasarkan observasi yang dilakukan oleh peneliti menunjukan bahwa kemampuan petugas pengelola Tempat Pelelangan Ikan (TPI) Tenda Kota Gorontalo masih rendah. Hal tersebut dapat ditunjukkan dari sebagian besar para pengelola TPI, mulai dari Kepala TPI tenda dan petugas lapangan rata-rata memiliki pengetahuan yang terbatas yaitu tingkat pendidikannya SLTA, dan belum pernah diikutkan dalam pelatihan-pelatihan khusus tentang pengelolaan dan pemanfaatan TPI. Kondisi tersebut sangat berdampak pada pemanfaatan TPI Tenda kurang maksimal. Kurangnya koordinasi yang dilakukan oleh pengelola TPI dengan Instansi terkait seperti Dinas Perikanan Kota Gorontalo, dan UPTD serta para nelayan. Misalnya dalam hal pemungutan retribusi bea ikan yang dipungut oleh petugas dari pedagang maupun nelayan tidak menentu pembayarannya sehingga nelayan seringkali mengeluh. Karena seringkali pungutan retribusi tidak ada karcisnya, sehingga kurang jelas pertanggungjawaban dari pihak pengelola TPI Tenda. Tanggung jawab petugas pengelola dalam pemanfaatan tempat pelelangan ikan juga masih rendah, karena selama ini pengelolaan dan pemanfaatan TPI Tenda belum menggunakan standar operasional prosedur (SOP) yang secara spesifik mengatur teknis pemanfaatan atau pengelolaan Tempat Pelelangan Ikan (TPI). Kondisi tersebut berdampak pada tugas-tugas organisasi yang dilakukan oleh petugas pengelola TPI kurang tepat sasaran. Sehingga hal ini dapat menjadi kendala dalam pemanfaatan TPI secara maksimal. Ditambah lagi aktivitas pelelangan tidak rutin digunakan oleh nelayan maupun pedagang ikan, selama ini nelayan enggan menjual hasil tangkapannya di TPI, karena harga TPI sangat rendah dan ikan tidak langsung dibayar kontan. Biasanya para pedagang cenderung menghutang hingga 1-2 minggu. Akibatnya nelayan lebih senang menjual hasil ikan di luar TPI. Kondisi ini sangat mempengaruhi pengembangan dan pengelolaan serta pemanfaatan TPI Tenda secara efektif.

Dari fenomena tersebut di atas penulis ingin mencoba mengungkapkan secara mendalam melalui sebuah pelitian ilmiah dengan judul penelitian tentang Kemampuan Petugas Pengelola dalam Pemanfaatan Tempat Pelelangan Ikan (TPI) di Kelurahan Tenda Kecamatan Hulonthalangi Kota Gorontalo.

\section{PERMASALAHAN}

Berdasarkan uraian latar belakang dan identifikasi masalah di atas, dapat dirumuskan masalah dalam penelitian ini yaitu Bagaimana 
PUBLIK: Jurnal Manajemen Sumber Daya Manusia, Administrasi dan Pelayanan Publik Sekolah Tinggi Ilmu Administrasi Bina Taruna Gorontalo Volume VI Nomor 1 Juni 2019

Kemampuan Petugas Pengelola dalam Pemanfaatan Tempat Pelelangan Ikan (TPI) di Kelurahan Tenda Kecamatan Hulonthalangi Kota Gorontalo?

\section{TUJUAN DAN MANFAAT PENELITIAN}

\section{Tujuan Penelitian}

Adapun tujuan yang diharapkan dalam penelitian ini yaitu untuk mengetahui Kemampuan Petugas Pengelola dalam Pemanfaatan Tempat Pelelangan Ikan (TPI) di Kelurahan Tenda Kecamatan Hulonthalangi Kota Gorontalo?

\section{Manfaat Penelitian}

Hasil penelitian ini diharapkan bermanfaat, baik ditinjau dari segi teoritis maupun praktis.

Manfaat dari segi teoritis, hasil penelitian ini dapat dijadikan sebagai bahan informasi bagi pengembangan ilmu pengetahuan sosial, khususnya ilmu administrasi Negara/Publik.

Manfaat praktis, hasil penelitian ini dapat dijadikan sebagai bahan pertimbangan bagi para pengambil kebijakan di Daerah khususnya di Kelurahan Tenda Kecamatan Hulonthalangi Kota Gorontalodalam rangka meningkatkan pendapatan masyarakat nelayan melalui pemanfaatan dan pengelolaan TPI.

\section{METODE PENELITIAN}

Jenis penelitian yang digunakan dalam penelitian ini adalah penelitan kualitatif yakni bertujuan untuk mendeskripsikan atau menggambarkan fakta-fakta di lapangan yang berkaitan dengan objek penelitian. Dalam penelitian kualitatif segala sesuatu yang akan dicari dari objek penelitian belum jelas dan pasti masalahnya, sumber datanya, hasil yang diharapkan semuanya belum jelas.

Dengan demikian pendekatan yang digunakan adalah fenomena yang terkait dengan Kemampuan Petugas Pengelola dalam Pemanfaatan Tempat Pelelangan Ikan (TPI) di Kelurahan Tenda Kecamatan Hulonthalangi Kota Gorontalo.

\section{Fokus Penelitian}

Adapun fokus penelitian dalam penelitian adalah kemampuan petugas pengelola dalam pemanfaatan tempat pelelangan ikan (TPI) dengan indikator sebagai berikut:

Pengetahuan yaitu tingkat pendidikan formal yang dimiliki oleh para petugas pengelola dalam mendukung pemanfaatan TPI di Kelurahan Tenda Kota Gorontalo;

Koordinasi yaitu koordinasi antara pengelola TPI dengan Instansi terkait, seperti Dinas

Kelautan dan Perikanan serta para nelayan dan pedagang ikan di TPI Tenda Kota Gorontalo;

Tanggung jawab yaitu kemampuan seseorang untuk menjalankan suatu kewajiban karena adanya dorongan di dalam dirinya, biasanya disebut juga dengan panggilan jiwa untuk melakukan sesuatu, termasuk dalam pemanfaatan TPI Tenda Kota Gorontalo. 


\section{HASIL PENELITIAN DAN PEMBAHASAN}

Variabel yang menjadi obyek kajian dalam penelitian ini ialah kemampuan petugas pengelola dalam pemanfaatan TPI di Kelurahan Tenda Kota Gorontalo. Untuk mengamati variabel tersebut di lapangan yakni di TPI Tenda Kota Gorontalo, digunakan fokus: pengetahuan, koordinasi, dan tanggung jawab. Pemaparan data penelitian berupa hasil wawancara dengan informan penelitian dipaparkan berdasarkan fokus tersebut.

Berikut ini adalah tahap pembahasan dari proses penelitian terkait kemampuan petugas pengelola dalam pemanfaatan TPI. Berdasarkan deskripsi hasil penelitian di atas mengenai kemampuan petugas pengelola dalam pemanfaatan TPI di Kelurahan Tenda Kota Gorontalo yang dilihat dari aspek pengetahuan, koordinasi, dan tanggung jawab dinilai belum menunjang atau belum optimal dilakukan.

Dilihat dari dimensi pengetahuan dalam penelitian adalah tingkat pendidikan formal dan non formal yang dimiliki oleh para petugas pengelola dalam menunjang pemanfaatan TPI di Kelurahan Tenda Kota Gorontalo. Hasil penelitian menunjukkan bahwa kemampuan petugas pengelola dalam pemanfaatan TPI di Kelurahan Tenda Kota Gorontalo yang dilihat dari aspek pengetahuan belum menunjang. Karena pengetahuan yang dimiliki oleh petugas TPI Tenda masih rendah, pendidikan formal yang pernah diikuti oleh petugas TPI rata-rata adalah tingkat pendidikan SLTA, serta kurang mendapatkan bimbingan teknis yang berhubungan dengan pengelolaan dan pemanfaatan TPI sebagai tugas pokok dan fungsi yang diembannya.

Dilihat dari dimensi koordinasi dalam penelitian ini merupakan koordinasi antara pengelola TPI dengan Instansi terkait, seperti Dinas Kelautan dan Perikanan serta para nelayan dan pedagang ikan di TPI Tenda Kota Gorontalo. Koordinasi juga merupakan suatu usaha yang sinkron dan teratur untuk menyediakan jumlah dan waktu yang tepat, dan mengarahkan pelaksanaan untuk menghasilkan suatu tindakan yang seragam dan harmonis pada sasaran yang telah ditentukan Terry (dalam Rivai 2014:23). Hasil penelitian menunjukan bahwa kemampuan petugas pengelola dalam pemanfaatan TPI di Kelurahan Tenda Kota Gorontalo yang dilihat dari aspek koordinasi belum menunjang atau belum optimal dilakukan. Hal ini terjadi karena Kepala TPI Tenda masih kurang melakukan koordinasi dengan intansi terkait, baik Dinas Perikanan dan Kelautan Provinsi dan Dinas Perikanan dan Kelautan Kota Gorontalo demikian juga dengan masyarakat nelayan. Belum maksimalnya koordinasi yang dilakukan oleh Kepala TPI dapat mempengaruhi pemanfaatan TPI Tenda kurang optimal.

Dilihat dari dimensi tanggung jawab dalam penelitian ini adalah kemampuan seseorang untuk menjalankan suatu kewajiban karena 
PUBLIK: Jurnal Manajemen Sumber Daya Manusia, Administrasi dan Pelayanan Publik Sekolah Tinggi Ilmu Administrasi Bina Taruna Gorontalo Volume VI Nomor 1 Juni 2019

adanya dorongan di dalam dirinya, biasanya disebut juga dengan panggilan jiwa untuk melakukan sesuatu, termasuk dalam pemanfaatan TPI Tenda Kota Gorontalo. Hasil penelitian menunjukan bahwa kemampuan petugas pengelola dalam pemanfaatan TPI di Kelurahan Tenda Kota Gorontalo yang dilihat dari aspek tanggung jawab masih kurang atau belum mendukung. Karena petugas belum menjalankan tugasnya sesuai dengan rencana, tugas-tugas yang dilaksanakan kurang memenuhi harapan organisasi, petugas dalam pengelolaan dan pemanfaatan TPI kadang-kadang tindakannya kurang memuaskan masyarakat dan terkesan kurang terbuka. Kondisi inilah yang menyebabkan pengelolaan dalam pemanfaatan TPI di Kelurahan Tenda Kota Gorontalo kurang optimal dan tidak sesuai dengan harapan.

Berdasarkan hasil analisis penelitian dan pembahasan yang telah diuraikan sebelumnya, secara keseluruhan bahwa penelitian mengenai kemampuan petugas pengelola dalam pemanfaatan TPI di Kelurahan Tenda Kota Gorontalo yang dilihat dari aspek pengetahuan, koordinasi, dan tanggung jawab belum menunjang atau belum optimal dilakukan. Hal ini terjadi karena petugas TPI Tenda dalam melaksanakan tugas pengelolaan dan pemanfaatan TPI kurang memiliki pengetahuan, koordinasi masih kurang, tanggung jawab masih kurang atau belum mendukung. Sehingga hal tersebut dapat mempengaruhi pemanfaatan dan pengelolaan TPI di
Kelurahan Tenda Kota Gorontalo tidak efektif dilakukan.

\section{KESIMPULAN}

Berdasarkan hasil penelitian dan pembahasan yang telah dipaparkan sebelumnya, maka dapat disimpulkan sebagai berikut.

Dilihat dari aspek pengetahuan belum menunjang.Karena pengetahuan yang dimiliki oleh petugas TPI Tenda masih rendah, pendidikan formal yang pernah diikuti oleh petugas TPI ratarata adalah tingkat pendidikan SLTA, serta kurang mendapatkan bimbingan teknis yang berhubungan dengan pengelolaan dan pemanfaatan TPI.

Dilihat dari aspek koordinasi belum menunjang atau belum optimal dilakukan. Karena Kepala TPI Tenda masih kurang melakukan koordinasi dengan intansi terkait, baik Dinas Perikanan dan Kelautan Provinsi dan Dinas Perikanan dan Kelautan Kota Gorontalo demikian juga dengan masyarakat nelayan.

Dilihat dari aspek tanggung jawab masih kurang atau belum mendukung. Karena petugas belum menjalankan tugasnya sesuai dengan rencana, tugastugas yang dilaksanakan kurang memenuhi harapan organisasi, petugas dalam pengelolaan dan pemanfaatan TPI kadang-kadang tindakannya kurang memuaskan masyarakat dan terkesan kurang terbuka. Kondisi inilah yang menyebabkan pengelolaan dalam pemanfaatan TPI di Kelurahan Tenda Kota Gorontalo kurang optimal dan tidak sesuai dengan harapan. 
PUBLIK: Jurnal Manajemen Sumber Daya Manusia, Administrasi dan Pelayanan Publik Sekolah Tinggi Ilmu Administrasi Bina Taruna Gorontalo Volume VI Nomor 1 Juni 2019

Secara umum penelitian mengenai kemampuan petugas pengelola dalam pemanfaatan TPI di Kelurahan Tenda Kota Gorontalo dilihat dari aspek pengetahuan, koordinasi, dan tanggung jawab belum menunjang atau belum optimal dilakukan.

\section{SARAN}

Dari kesimpulan-kesimpulan di atas, peneliti mengajukan saransaran sebagai berikut:

Perlunya pimpinan dan staf TPI untuk dapat meningkatkan pengetahuan melalui pendidikan formal dan non formal, agar memiliki wawasan dan kemampuan dalam melaksanakan tugas yang di embannya.

Perlunya pimpinan dan staf TPI dalam melakukan pengelolaan dan pemanfaatan TPI untuk melakukan koordinasi dan singronisasi secara intensif kepada instansi terkait dan masyarakat, agar terwujud kerjasama yang harmonis dalam mengembangan TPI ke depan yang lebih cerah dan sesuai harapan.

Perlunya pimpinan dan staf TPI memiliki tanggung jawab yang tinggi dalam pelaksanaan tugas, agar rencana yang telah ditetapkan dapat terwujud dengan baik.

Pentingnya pemerintah daerah dan pemerintah pusat untuk dapat memperhatikan TPI, khususnya TPI Tenda dalam hal penambahan fasilitas sarana penunjang serta anggaran operasional dan anggaran pengembangan TPI.

\section{DAFTAR PUSTAKA}

Caizi, N. 2012. Reformasi Administrasi Publik. Jakarta: PT. Grasindo

Creswell, John W. 2010. Research Design, Pendekatan Kualitatif Kuantitatif, dan Mixed. Edisi Ketiga. Cetakan Pertama. Yogyakarta: Pustaka Pelajar.

Daft, 2006. Era Baru Manajemen. Edisi 9 Buku 2. Jakarta: Salemba Empat.

Gibson, James L., John M. Ivancevich dan James H. Donnely Jr. 2009. Organisasi: Perilaku, Struktur, Proses. (Terjemahan) Edisi Delapan. Jakarta: Aksara.

Handoko, T. Hani. 2008. Manajemen Personalia \& Sumber Daya Manusia. Cetakan Keenam Belas. Yogyakarta: BPFE UGM.

Haryadi, Hendi. 2009. Administrasi Perkantoran Untuk Manajer \& Staf. Cetakan Pertama. Jakarta: Visimedia

Hasibuan, Melayu S.P. 2009. Manajemen Sumber Daya Manusia. Edisi Revisi, Jakarta: Bumi Aksara.

Jones, Gareth R. 2010. Organizational Theory, Text and Cases. Wesley Publishing Company. Reading Massachusets, USA

Manullang. 2008. Dasar-Dasar Manajemen. Cet. Kedelapan Belas. Yogyakarta: Gadjah Mada University Press.

Moleong, Lexy J. 2014. Metodologi Penelitian Kualitatif. Cet. Ketiga Puluh dua. Bandung: PT. Remadja Rosdakarya.

Mathis, Robert L \& Jackson, John H. 2006. Human Resource 
PUBLIK: Jurnal Manajemen Sumber Daya Manusia, Administrasi dan Pelayanan Publik Sekolah Tinggi Ilmu Administrasi Bina Taruna Gorontalo Volume VI Nomor 1 Juni 2019

Management. Edisi ke-10.

Jakarta: Salemba Empat.

M. Kamarudin. 2013. Pengelolaan

Tempat Pelelangan Ikan (TPI)

dalam Menunjang Keberdayaan

Masyarakat Nelayan di TPI

Pelabuhan Perikanan Nusantara

(PPN) Prigi Desa Tasikmadu, Kabupaten Trenggalek, Provinsi Jawa Timur.

Nawawi, Handari. 2009. Manajemen

Sumber Daya Manusia. Cetakan ketiga. Yogyakarta: Gama Press.

Noe, Hollenbeck, Gerhart, \& Wright. 2008. Fundamentals of Human Resources Management. New York: McGraw-Hill.

Notoatmodjo, Soekidjo. 2009. Pengembangan Sumber Daya Manusia. Jakarta: PT. Rineka Cipta. 